\title{
Non-target screening of organic compounds in offshore produced water by GCXGC-MS
}

\author{
Sofie N Bergfors ${ }^{1}$, Khoa Huynh ${ }^{1}$, Annette E Jensen ${ }^{1}$, Jonas Sundberg ${ }^{\text {Corresp. } 1}$ \\ ${ }^{1}$ Danish Hydrocarbon Research and Technology Centre, Technical University of Denmark, Kgs. Lyngby, Denmark \\ Corresponding Author: Jonas Sundberg \\ Email address: jonsun@dtu.dk
}

Produced water is the largest by-product of oil and gas production. At off-shore installations, the produced water is typically reinjected or discharged into the sea. The water contains a complex mixture of dispersed and dissolved oil, solids and inorganic ions. A better understanding of its composition is fundamental to 1 ) improve environmental impact assessment tools and 2 ) develop more efficient water treatment technologies. The objective of the study was to screen produced water sampled from a producing field in the Danish region of the North Sea to identify any containing organic compounds. The samples were taken at a test separator and represent an unfiltered picture of the composition before cleaning procedures. The analytes were isolated by liquid-liquid extraction and derivatized using a silylation reagent to increase the volatility of oxygenated compounds. The final extracts were analyzed by comprehensive multi-dimensional gas chromatography coupled to a high-resolution mass spectrometer. A non-target processing workflow was implemented to extract features and quantify the confidence of library matches by correlation to retention indices and the presence of molecular ions. Approximately 120 unique compounds were identified across nine samples. Of those, 15 were present in all samples. The main types of compounds are aliphatic and aromatic carboxylic acids with a small fraction of hydrocarbons. The findings have implications for developing improved environmental impact assessment tools and water remediation technologies. 


\section{Non-target screening of organic compounds in} 2 offshore produced water by GCXGC-MS

3

4 Sofie Nitsche Bergfors ${ }^{1}$, Khoa Huynh ${ }^{1}$, Annette Eva Jensen ${ }^{1}$, Jonas Sundberg ${ }^{1}$

5

61 Danish Hydrocarbon Research and Technology Centre, Technical University of

7 Denmark, Kgs. Lyngby, Denmark

8

9 Corresponding author:

10 Jonas Sundberg 1

11

12 Email address: jonsun@dtu.dk 


\section{Introduction}

14 Produced water is by volume the largest byproduct in oil and gas production. For reservoirs on the Danish continental shelf, where production is often supported by water flooding, the volume of produced water typically exceeds the volume of oil (The Danish Energy Agency, 2014). This water contains a complex mixture of inorganic and organic compounds. Implementation of offshore water management strategies is challenging due to the large volumes and practical limitations on infrastructure. Current procedures consist of cleaning of the produced water, followed by discharge into the sea or reinjection in producing or disposal wells (Lyngbaek \& Blidegn, 1991; Røe \& Johnsen, 1996; Røe Utvik, 1999; Durell et al., 2004). For discharge, the OSPAR Convention, which was set in to force in 1998, sets a limit of $30 \mathrm{mg}$ of dispersed oil per liter of water as an annual average (OSPAR Commission, 2001). There is currently no limit on the dissolved compounds. Furtthermore, detailed knowledge on their structure and abundance is lacking.

In simplified terms, produced water can be seen as the product of aqueous extraction of crude oil by mixing within the reservoir and during production. In reality, the process is complex and the composition is highly dependent on reservoir properties, field history and water injection strategies (Bergfors, Schovsbo \& Feilberg, 2020). For example, studies have shown that salinity influences to the organic content, likely caused by a salting-out effect (Barth, Borgund \& Riis, 1990; Barth, 1991; Barth \& Riis, 1992; Endo, Pfennigsdorff \& Goss, 2012; Dudek et al., 2020). At the producing platform, a gravitational separation of oil, water and gas is carried out. The resulting water phase contains dissolved and dispersed oil droplets. The latter is largely removed by physical methods, i.e. separators, hydrocyclones and gas flotation tanks/degassers implemented in series on the platform, typically resulting in levels below $10 \mathrm{mg} / \mathrm{L}$ at the discharge point (Meldrum, 1988; Saththasivam, Loganathan \& Sarp, 2016; Durdevic \& Yang, 2018). In contrast, the removal of dissolved organics requires chemical treatment, e.g. degradation via advanced oxidation processes (AOPs) (Jiménez et al., 2019; Lin et al., 2020; Liu et al., 2021). This is challenging to implement on offshore installations due to safety and the requirement of low residency times. Furthermore, the current generation of AOPs are mainly based on Fenton's reagent which produces toxic chlorinated byproducts when applied to saline water (Kiwi, Lopez \& Nadtochenko, 2000; De Laat \& Le, 2006; Sirtori et al., 2012). The goal of produced water management is not necessarily zero discharge but zero harmful discharge. Improved knowledge of its composition is thus not only beneficial to develop environmental impact assessment tools. The information may also be used to develop improved and targeted treatment methods, i.e specific removal of harmful components, and not total organic content. This has the potential to increase efficiency and reduce the cost of water management strategies. 
54 Ultimately, the toxicity of the produced water is a complex function based on the 55 structure and concentration of both the dispersed and dissolved oil components 56 (Strømgren et al., 1995; Bakke, Klungsøyr \& Sanni, 2013; Niu et al., 2016; Lofthus et 57 al., 2018). Furthermore, inorganic species such as heavy metals should be taken into 58 consideration. We argue that to fully understand the effect of organic compounds in

59

60

61

62

63

64

65

66

67

68

69

70

71

72 produced water discharge, we must 1) carry out full structural characterization studies and 2) differentiate between dispersed and dissolved species and 3) develop methods to integrate the data into environmental impact assessment tools. Although numerous compounds in produced water have been identified as part of ongoing water quality studies, a large part of the chemical space remains unknown. Recent advances in analytical technology (i.e. multi-dimensional chromatography, high-resolution mass spectrometry) have allowed more in-depth studies of the organic composition (Samanipour et al., 2019, 2020; Sørensen et al., 2019; Dudek et al., 2020). However, these studies mainly focus on general classes of naphthenic acids and are based on formula calculations of exact masses without further structural elucidations. Sørensen et. al. (2019) described a non-target screening study but did not provide details beyond compound classes (i.e. phenols vs. naphthalenes). Thus, a large knowledge gap in the identity of dispersed and dissolved organics still exists.

To narrow this gap we have carried out a non-target screening study. The objective was not to evaluate the efficiency of implemented cleaning procedures but to obtain an "unfiltered" picture of the water composition immediately after production. Several samples were obtained from the test separator of a producing platform in the Danish North Sea. The organics were extracted by liquid-liquid extraction (LLE) using dichloromethane (DCM). The extracts were derivatized to increase the volatility of oxygenated compounds and analyzed using comprehensive multidimensional gas chromatography $(\mathrm{GC} \times \mathrm{GC})$ coupled with a high-resolution quadrupole-time of flight mass spectrometer (MS). One advantage of using GC-MS as compared to liquidchromatography (LC)-MS is the possibility of identification by spectral matching using commercially available libraries. In contrast, LC-MS is significantly dependent on usergenerated libraries based on reference compounds as the ionization efficiency is more dependent on experimental conditions (Schymanski et al., 2015). Approximately 1500 compounds were detected per sample, with 120 unique compounds tentatively identified across all samples. To increase the confidence of library matches, a data processing workflow that implemented retention indices and accurate mass matching was implemented. The data were analyzed to obtain a broad knowledge of the types of compounds present, their relative abundance as well as common compounds present across all samples. 


\section{Materials \& Methods}

94 Chemicals and reagents

95 Benzoic acid, phenol, cycolhexanecarboxylic acid, octanoic acid, dichloromethane

96 (LiChroSolv, Merck), $n$-hexane (SupraSolv for gas chromatography MS, Merck),

97 magnesium sulfate (ReagentPlus, Redi-Dri, Sigma Aldrich), N,O-

98 bis(trimethylsilyl)trifluoroacetamide containing $1 \%$ of trimethylchlorosilane

99 (BSTFA+TMCS, Supelco) were used as received. Deuterated internal standards

100 (naphthalene- $d_{8}$, acenaphthene- $d_{10}$, phenanthrene- $d_{10}$, chrysene- $d_{12}$, Supelco analytical

101 standards) were used to monitor retention time shifts. ${ }^{1} \mathrm{D}$ retention index calibration was

102 performed using a linear C7 to C30 saturated alkanes mixture (Supelco, TraceCERT,

103 Sigma Aldrich). High purity water was obtained from a Milli-Q Advantage A10 unit. All

104 chemicals and reagents were used as received.

105

106

107

108

109

\section{Sampling and sample preparation}

Produced water samples were donated by Mærsk Oil \& Gas (now Total E\&P). The samples were acquired from a producing field (water-injected) located in the Danish region of the North Sea. The sampling campaign took place between June 2018 and February 2019. The samples were taken at irregular intervals with no replicates. Water samples were collected at the test separator on the production platform following protocols established by the operator. The test separator is a simple gravity-based three-phase separator where the water settles below the oil and can be sampled. No cleaning or further processing of the samples was carried out at the platforms. The samples were received in plastic bottles $(1 \mathrm{~L})$, aliquoted $(500 \mathrm{~mL})$, and immediately treated with dilute hydrochloric acid $(18 \%, 1 \mathrm{~mL}$ per $100 \mathrm{~mL}$ sample) for a final $\mathrm{pH}<2$. Nine samples from the received batch were selected for analysis. The samples were selected due to the absence of dispersed oil droplets as evaluated by visual inspection (using microscope). The samples were stored in the dark at $4{ }^{\circ} \mathrm{C}$ until extraction and analysis.

121

122

Three aliquots $(50 \mathrm{~mL})$ of each produced water sample were extracted using separate glassware. The aliquots were filtered through a $0.45 \mu \mathrm{m}$ PTFE-filter to remove solids and particles. Each $50 \mathrm{~mL}$ aliquot was extracted with DCM $(50 \mathrm{~mL})$. The organic phase was washed with saturated aqueous sodium chloride $(50 \mathrm{~mL})$ and carefully removed in vacuo. The residue was reconstituted in $n$-hexane $(1.5 \mathrm{~mL})$ and dried over $\mathrm{MgSO}_{4}$. An aliquot $(1000 \mu \mathrm{L})$ of the sample was transferred to a $2 \mathrm{~mL}$ vial, combined with

128 deuterated internal standards (for monitoring of retention time stability), combined with BSTFA+TMCS $(50 \mu \mathrm{L})$ and incubated at $70^{\circ} \mathrm{C}$ for 30 minutes, whereafter, it was allowed to return to room temperature. The derivatized sample was further diluted tenfold with $n$-hexane and immediately analyzed on the GC×GC-MS. 


\section{Extraction recovery and reproducibility}

134 A model produced water containing five representative model compounds (benzoic

135 acid, phenol, 2-naphthoic acid, cyclohexanecarboxylic acid, and octanoic acid, each at 5

$136 \mathrm{ppm}$, total organics $25 \mathrm{ppm}$ ) in synthetic formation water (see supplemental information)

137 was prepared to establish variability in the sample preparation protocol and instrumental

138 analysis. The concentration of total organics was chosen to emulate typical levels

139 encountered at production platforms. The model water was extracted four times in two

140 batches following an identical procedure as for the produced water samples. Three

141 procedural blanks were prepared to establish background levels and experimental

142 sources of contamination.

143

144

145

146

147

148

149

150

151

152

153

154

155

156

157

158

159

160

161

162

163

164

165

166

167

168

\section{GCXGC-MS Analyses}

GC×GC-MS data were acquired using an Agilent 7890B GC coupled to a 7200B QTOF high-resolution mass spectrometer (Agilent Technologies, Palo Alto, CA, USA). The system was equipped with a Zoex ZX-2 thermal modulator (Zoex Corporation, Houston, TX, USA). The separation was achieved using a combination of an Agilent DB-5MS UI $\left({ }^{1} \mathrm{D}, 30 \mathrm{~m}, 0.25 \mathrm{~mm}\right.$ i.d., $0.25 \mu \mathrm{m} \mathrm{d}$ ) and a Restek Rxi-17Sil MS ( ${ }^{2} \mathrm{D}, 2 \mathrm{~m}, 0.18 \mathrm{~mm}$ i.d., $0.18 \mu \mathrm{m}_{\mathrm{f}}$ ) capillary columns connected using a SilTite $\mu$-union. The oven was temperature programmed as follows; $1 \mathrm{~min}$ hold-time at $50{ }^{\circ} \mathrm{C}$, ramp to $320^{\circ} \mathrm{C}, 3{ }^{\circ} \mathrm{C}$ $\mathrm{min}^{-1}$ in constant flow mode $(1 \mathrm{~mL} / \mathrm{min})$. The modulation period was set to $3 \mathrm{~s}$ with a 400 $\mathrm{ms}$ hot-jet duration. The MS transfer line was held at $280^{\circ} \mathrm{C}$. The MS acquired spectra in electron ionization mode $(70 \mathrm{eV})$ with a mass range of $45-500$ and an acquisition speed of $50 \mathrm{~Hz}$. The instrument was operated in its $2 \mathrm{GHz}$ sampling rate mode to increase the dynamic range. Automatic mass calibration was performed for every $5^{\text {th }}$ sample (approximately 7.5 hours).

\section{Data processing}

Baseline correction (Reichenbach et al., 2003), peak detection and library search were performed using GC Image v2.8.3 (Zoex, Houston, TX). Mass spectra were matched against the NIST Mass Spectral Library (National Institute of Standards and Technology, 2017 edition) with a minimum match factor of 700. All compound tables were exported as comma-separated texts for external processing. A data processing workflow was implemented in Python (Python Software Foundation. Python Language Reference, version 3.7.4. Available at http://www.python.org). The script is available as supplementary information deposited in a Zenodo repository (doi://

169 10.5281/zenodo.4009045).

\section{Sample preparation and analyses}


172 Previous studies on dissolved organics in oilfield produced water have employed LLE or 173 solid-phase extraction (SPE) (Thomas et al., 2009; Kovalchik et al., 2017; Barros et al., 174 2018; Samanipour et al., 2019). For produced water, LLE using DCM has been shown 175 to have a similar recovery as SPE (Samanipour et al., 2019). The main difference was 176 observed in the size distribution, where larger species tend to have a higher recovery 177 using SPE due to their low solubility in DCM. LLE is non-discriminative in comparison to 178 SPE which is used to fractionate compound classes based on adsorption

179 characteristics. Thus, it allowed us to extract the broad range of organics present in produced water. Furthermore, the Norwegian Oil and Gas specialist network recommends LLE for the quantification of phenols in produced water (Norwegian Oil and Gas, 2012). Thus, it would allow us to 'see' what is missing using routine targeted analyses. Approximately 30 samples were received as part of the campaign.

184 The water samples had varying levels of oil, likely due to the sampling and status of the test separator. Samples that contained a clear separate layer of oil, including smaller amounts, were excluded from the study to minimize the risk of contamination (Figure 1). Optical inspection of these samples showed that they contained large amounts of dispersed oil droplets, even when sampling below the oil layer (Figure 2). After exclusion, 9 samples were chosen to be included in the study with extraction and characterization. All samples were filtered through a $0.45 \mu \mathrm{m}$ PTFE-filter to remove insoluble material and particles. A small aliquot $(50 \mathrm{~mL})$ of each sample was extracted in triplicate using an equivalent volume of DCM.

The dissolved components of produced water were largely expected to be oxygenated organics, i.e. alcohols (mainly phenols) and acids. To increase the volatility of the aforementioned compounds, the samples were silylated. After removal of the solvent invacuo, each sample was reconstituted in $1.5 \mathrm{~mL}$ of $n$-hexane. A $1 \mathrm{~mL}$ aliquot of the reconstituted extract was treated with BSTFA-TMCS and incubated at $70^{\circ} \mathrm{C}$ for 30 minutes. After derivatization, the samples were further diluted ten-fold, meaning that the samples ultimately were concentrated approximately three-fold (from $50 \mathrm{~mL}$ to $15 \mathrm{~mL}$ ). The final concentration factor was chosen as a compromise between the detection of

202 trace compounds and avoiding column and detector overload. Due to the large concentration range of our analytes, it would be beneficial to run each sample at multiple dilution factors. However, due to the long run time (90 minutes) and the number of extraction replicates (3) this was not feasible due to time constraints. It is important to 206 remember that this strategy has two effects; 1) high concentration compounds may overload the detector with spectral skewing and poor library match as result, and 2) trace-compounds may be diluted to a level below the limit of detection.

209

210

Three procedural blanks were extracted and analyzed to determine background levels and potential sources of contamination. Minor amounts of fatty acids were detected in 
212 addition to a series of polysiloxanes (discrete peaks, not common column bleed). The 213 source of the latter could not be identified but as it lacked retention in the ${ }^{2} \mathrm{D}$ it did not 214 interfere with our analytes of interest. To establish recovery and repeatability, a model 215 produced water was prepared by spiking four organic acids and phenol into synthetic 216 formation water (see Experimental section and supplemental data). All model

217 compounds were detected in one or more produced water samples. The model water 218 was extracted in four replicates. The recovery values were calculated based on peak 219 volumes in comparison to those obtained by analyzing pure stock solutions (Table 1).

220 The recovery varied from $36 \%$ for benzoic acid up to $90 \%$ for phenol. Considering the 221 multi-step sample extraction, including a derivatization reaction, this was deemed acceptable. The relative standard deviation of the peak volumes (measured after baseline correction using the GC Image package) of model compounds as detected in a representative produced water sample varied from $2 \%$ to $23 \%$ (calculated from three extraction replicates).

226

\section{Chromatography}

228 Crude oil is an ultracomplex mixture of saturated and aromatic hydrocarbons with a smaller fraction of N,S,O-containing compounds (Marshall \& Rodgers, 2004; Hsu et al., 2011; Palacio Lozano et al., 2020). This complexity will be reduced but reflected in the produced water. Based on previous studies of Danish oils we know that the dominant

232 oxygenated species belong to the $\mathrm{O} 1$ and $\mathrm{O} 2$ classes with a large diversity in aromaticity (Sundberg \& Feilberg, 2020). Thus, the compositional variation in the produced water was assumed to be dominated by carbon number and level of saturation. Ultimately, the boiling point range was assumed to be larger than the variation in saturated versus aromatic structures. Therefore, we choose to use a nonpolar column in the ${ }^{1} \mathrm{D}$ (providing the highest separation power) with a shorter medium polarity column in the ${ }^{2} \mathrm{D}$. Conventional polar columns are based on polyethyleneglycol (PEG) chemistry and are incompatible with silylation reagents. Therefore, we choose to use a $50 \%$-phenyl-type column where aromaticity is the largest factor affecting retention. By using this column combination, the retention in both dimensions will increase with aromaticity. For example, cyclohexane acetic acid has a retention of 17.2 $\mathrm{min} / 0.84 \mathrm{~s}$ in ${ }^{1} \mathrm{D} /{ }^{2} \mathrm{D}$ as compared to $24.6 \mathrm{~min} / 1.33 \mathrm{~s}$ for benzeneacetic acid (measured as the corresponding trimethylsilyl esters). In contrast, alkylation of a core aromatic or saturated structure will only affect retention in the ${ }^{1} \mathrm{D}$. For example, phenol and its alkylated homologs (methyl, ethyl and propyl) have ${ }^{1} \mathrm{D}$ retention times of $13.4,16.9$, 19.9 and 23.3 minutes, respectively, where the retention in ${ }^{2} \mathrm{D}$ is within 0.89 to 0.95 seconds. By investigation of a typical chromatogram, two things become obvious; 1 ) the desired separation of saturates, mono- and diaromatics is achieved and 2) a large portion of the ${ }^{2} \mathrm{D}$ space is relatively uncopied due to the small number of polycyclic 
251 species where the majority of aromatics are benzene derivatives. A representative

252 chromatogram with selected analytes marked is presented in Figure 3.

253

254 A $3{ }^{\circ} \mathrm{C} \mathrm{min}^{-1}$ temperature gradient was found to be the optimal compromise between

255 peak width, resolution and run time. At this rate, the typical peak width was $10 \mathrm{~s}$ in the

256 first dimension. Thus, using a modulation period of $3 \mathrm{~s}$ allowed us to obtain the

257 recommended minimum of three modulations per peak (Murphy, Schure \& Foley, 1998).

258 Due to instrumental complexity and long run times, retention time shifts are commonly

259 observed both in inter-sample and inter-batch runs. Deuterated PAH standards were

260 used to monitor retention times over time. The ${ }^{1} \mathrm{D} / 2 \mathrm{D}$ retention time variability is

261 presented in Table 1 . Both ${ }^{1} \mathrm{D}$ and ${ }^{2} \mathrm{D}$ were shown to be stable over the whole analyses

262 run, covering 27 seven injections ( 9 samples with three extraction replicates) and 7

263 days.

264

265

266

267

268

269

270

271

272

273

274

275

276

277

278

279

280

281

282

283

284

285

Non-target screening and compound identification

Approximately 1500 compounds were detected in each sample. A data processing workflow was implemented to sort, organize and score the data. A schematic representation is presented in Figure 4. The associated files are available as supplementary information. The detected features were matched against the NIST EI Mass Spectral Library (2017). All compounds with a match factor below 700 were removed. To increase the annotation confidence, two additional factors were included; retention index (Kovats) and the presence of the molecular ion. To quantify the identification confidence the following scoring rules were implemented:

1. A match factor above 800 gives a score of 10 points.

2. A match factor between 700 and 800 gives a score of 5 points.

3. A retention index match within 50 units gives a score of 5 points.

4. The detection of the molecular ion within $20 \mathrm{ppm}$ mass accuracy gives a score of 5 points.

A total score of above 10 was (i.e. match factor of a minimum of 700 and either a retention index and or molecular ion match) was classified as a probable match, whereas a total score below 10 was classified as a tentatively identified structure (Schymanski et al., 2014). To reduce experimental errors, only features that were present in all three replicates were included in the final table of compounds.

286 Furthermore, all duplicate compounds were removed. This is a crude step that 287 inherently removes, for example, isomeric species which would not be differentiated using automatic library search. However, for our purpose the identification of isomers is not an inherent goal. The aim of the study was to identify the presence of broad compound-class types and dominant species. The correct identification of isomeric 
291 species or species with highly similar fragmentation patterns requires manual

292 intervention and is beyond the scope of this study.

293

294 The workflow reduced the number of features from approximately 1) 1500 detected to 2)

295200 library hits with match factor > 700, to 3) 50 - 70 when with duplicates based on

296 name were removed. Ultimately, the merging of inter-sample features resulted in 120

297 unique hits across all samples. Of those, 42 had the maximum score of 20 (i.e. match

298 factor $>800$, molecular ion detected and retention index within 50 units). Near all (87\%)

299 identified compounds are oxygen-containing, with amines, sulfides and hydrocarbons

300 being the remaining constituents. Only 15 compounds (after removal of internal

301 standards and background species) were present in all samples (Table 2).

302

303

304

305

306

307

308

309

310

311

312

313

\section{Discussion}

A few papers have previously described non-target screening of produced water, primarily from the Norwegian continental shelf. Sørensen et. al. described the characterization of unpurified DCM extracts with comparisons to the polar and non-polar fractions as isolated by SPE (Sørensen et al., 2019). In their study, a high concentration of hydrocarbons including naphthalenes and linear alkanes was detected in the produced water. This is in contrast to our study, where only a few hydrocarbons, in relative trace amounts, were observed as measured by extracted ion chromatograms of known species. The aqueous solubility of saturated hydrocarbons is low. However, BTEX-type (benzene, toluene and xylene) compounds have relatively high solubility but were still not identified. Furthermore, hydrocarbons could be present in the water phase as dispersed oil droplets. We observed that the presence of such droplets in a water sample is heavily dependent on the oil-water ratio and that optical inspection using a microscope was required for their detection. Oil droplets were not observed in the samples included in our study which we believe explain why only small amounts of hydrocarbons were detected. A second explaination could be losses during sample transport and storage, either via volatilization/diffusion through the plastic container or microbial degradation. However, this cannot be validated without further sampling with

322 more control of the process.

324

Only a small fraction of the detected compounds were identified with an acceptable confidence level. 36 unique compounds (across all samples) received the maximum

326 identification score, i.e. a match factor $>800$, retention index match and detection of the molecular ion. The match factor had the most severe impact on feature reduction. Lowering the match factor limit to $>600$ increased the number of tentatively identified features by approximately $40 \%$ (compared to match factor $>700$ ). A manual evaluation showed that although several hits were chemically reasonable based on structure and 330 retention index, the lower limit also led to multiple apparent false positives. Added 
331 confidence to questionable identities could be obtained by a corroborative study using

332 soft ionization techniques, i.e. chemical ionization or low voltage electron ionization,

333 where the molecular ion is better observed for non-aromatic species.

334

335

336

337

Looking at the obtained data, two conclusions were made; 1) samples were dominated

338 by oxygenated organics, and 2) sample-to-sample variation was large, both in terms of composition and relative abundance. Oxygenated hydrocarbons form during diagenesis

339 but may also be the result of microbial and or chemical processes during oil production

340 (Aitken, Jones \& Larter, 2004; Head, Gray \& Larter, 2014; Pannekens et al., 2019). The oxygenation leads to high partitioning into the aqueous phase during oil-water separation, and these compounds will likely require attention when developing successful water management technologies. Approximately $50 \%$ of the compounds were aromatic, primarily benzene-derivatives with few naphthalenes present. The molecular structure of six representative compounds are presented in Figure 5. Some of the identified compounds are suspected residual production chemicals, e.g. hexadecanol which does not occur naturally in crude oil. Even when comparing two samples that were sampled from the same well and only three days apart, the difference was substantial. As we lack more detailed information on the sampling step, it is difficult to conclude where these differences stem from. The intra-sample variation can be an effect of sampling and oil-to-water ratio in the test separator. The level of dispersed and or layered oil in samples will likely influence the aggregation and solubility of organics in the aqueous phase. A more controlled sampling campaign is required to identify the source of variability.

\section{Conclusions}

357

The composition of produced water is highly complex with several unknowns. Our study aimed to narrow this gap by a broad identification of dissolved organics. The implemented identification workflow excluded approximately $95 \%$ of the detected compounds (1000 - 1500 per sample), resulting in 50-80 tentatively identified compounds per sample. This demonstrates both the power and pitfalls of non-target screening; more than 100 compounds were identified with an acceptable level of confidence, and more than 1000 compounds remain unknown. To our knowledge, this is the most comprehensive list of identified compounds in produced water that has been publicly published. However, being a screening study, quantification was not carried out for any compounds. As this is an important factor for environmental assessment, the obtained compound lists should be used to develop targeted methods to look at absolute concentrations. Furthermore, it would be beneficial to reduce the number of unknowns by using complementary techniques (e.g. HPLC-MS and other soft ionization methods), improved custom libraries and in-silico mass spectral prediction. 
371 When performing environmental impact assessments, both structure and concentration

372 have to be taken into consideration (Tang et al., 2019). A large part of the detected

373 compounds are present at trace levels. Their concentration will be further reduced at

374 discharge to sea where a rapid dilution to a large body of water occurs. However,

375 potential cocktail effects where the combined effect of a series of micro-pollutants is

376 harmful but not the single species should be accounted for (Di Poi et al., 2018). Here, it

377 would be highly beneficial to link non-target screening studies with toxicological

378 measurements. Ultimately, we hope that our study contributes a small piece of the

379 puzzle, and a stepping stone towards further studies to uncover the full picture.

380

\section{Author contributions}

383

J.S conceptualized the study, developed the analytical methodology and sample

384 preparation workflow. S.B and A.J carried out the experimental work and sample extractions. A.K carried out method validation and recovery studies. J.S developed the

386

387 data processing workflow and wrote the code. S.B and J.S analyzed the data and wrote the manuscript. All authors performed scientific and grammatical revisions of the final

388 draft.

390

391

392

393

394

395

396

397

398

399

400

401

402

403

404

405

406

407

408

409

410

411

\section{Acknowledgments}

The authors are grateful for the financial support received from the Danish Hydrocarbon Research \& Technology Centre (DHRTC) under the Reservoir Fluids Characterization and Produced Water Management programs. The authors are also grateful for the donation of the samples from Total E\&P Denmark. Furthermore, the authors kindly acknowledge the Danish Underground Consortium (Total, E\&P Denmark, Noreco \& Nordsøfonden) for granting permission to publish this work. Finally, the authors are grateful for fruitful and constructive feedback on the manuscript from Simon Ivar Andersen.

\section{References}

Aitken CM, Jones DM, Larter SR. 2004. Anaerobic hydrocarbon biodegradation in deep subsurface oil reservoirs. Nature 431:291-294. DOI: 10.1038/nature02922.

Bakke T, Klungsøyr J, Sanni S. 2013. Environmental impacts of produced water and drilling waste discharges from the Norwegian offshore petroleum industry. Marine Environmental Research 92:154-169. DOI: 10.1016/j.marenvres.2013.09.012.

Barros E V., Dias HP, Pinto FE, Gomes AO, Moura RR, Neto AC, Freitas JCC, Aquije GMF V., Vaz BG, Romão W. 2018. Characterization of Naphthenic Acids in Thermally Degraded Petroleum by ESI(-)-FT-ICR MS and $1 \mathrm{H}$ NMR after SolidPhase Extraction and Liquid/Liquid Extraction. Energy \& Fuels 32:2878-2888. DOI: 10.1021/acs.energyfuels.7b03099.

Barth T. 1991. Organic acids and inorganic ions in waters from petroleum reservoirs, Norwegian continental shelf: a multivariate statistical analysis and comparison with 
440

441

442

443

444

445

446

447

448

449

450

451

452

453

454

455

456

457

American reservoir formation waters. Applied Geochemistry 6:1-15. DOI: 10.1016/0883-2927(91)90059-X.

Barth T, Borgund AE, Riis M. 1990. Organic acids in reservoir waters-Relationship with inorganic ion composition and interactions with oil and rock. Organic Geochemistry 16:489-496. DOI: 10.1016/0146-6380(90)90064-7.

Barth T, Riis M. 1992. Interactions between organic acids anions in formation waters and reservoir mineral phases. Organic Geochemistry 19:455-482. DOI: 10.1016/0146-6380(92)90012-M.

Bergfors SN, Schovsbo NH, Feilberg KL. 2020. Classification of and changes within formation water types in Danish North Sea Chalk: A study of the Halfdan, Dan, Kraka and Valdemar oil reservoirs. Applied Geochemistry:104702. DOI: 10.1016/j.apgeochem.2020.104702.

Dudek M, Vik EA, Aanesen SV, Øye G. 2020. Colloid chemistry and experimental techniques for understanding fundamental behaviour of produced water in oil and gas production. Advances in Colloid and Interface Science 276:102105. DOI: 10.1016/j.cis.2020.102105.

Durdevic P, Yang Z. 2018. Dynamic Efficiency Analysis of an Off-Shore Hydrocyclone System, Subjected to a Conventional PID- and Robust-Control-Solution. Energies 11:2379. DOI: 10.3390/en11092379.

Durell G, Johnsen S, Røe-Utvik T, Frost T, Neff J. 2004. Produced Water Impact Monitoring In The Norwegian Sector Of The North Sea: Overview Of Water Column Surveys In The Three Major Regions. In: SPE International Conference on Health, Safety, and Environment in Oil and Gas Exploration and Production. Society of Petroleum Engineers,. DOI: 10.2118/86800-MS.

Endo S, Pfennigsdorff A, Goss K-U. 2012. Salting-Out Effect in Aqueous $\mathrm{NaCl}$ Solutions: Trends with Size and Polarity of Solute Molecules. Environmental Science \& Technology 46:1496-1503. DOI: 10.1021/es203183z.

Head IM, Gray ND, Larter SR. 2014. Life in the slow lane; biogeochemistry of biodegraded petroleum containing reservoirs and implications for energy recovery and carbon management. Frontiers in Microbiology 5. DOI: 10.3389/fmicb.2014.00566.

Hsu CS, Hendrickson CL, Rodgers RP, McKenna AM, Marshall AG. 2011. Petroleomics: advanced molecular probe for petroleum heavy ends. Journal of Mass Spectrometry 46:337-343. DOI: 10.1002/jms.1893.

Jiménez S, Andreozzi M, Micó MM, Álvarez MG, Contreras S. 2019. Produced water treatment by advanced oxidation processes. Science of The Total Environment 666:12-21. DOI: 10.1016/j.scitotenv.2019.02.128.

Kiwi J, Lopez A, Nadtochenko V. 2000. Mechanism and Kinetics of the OH-Radical Intervention during Fenton Oxidation in the Presence of a Significant Amount of Radical Scavenger (Cl - ). Environmental Science \& Technology 34:2162-2168. DOI: 10.1021/es991406i.

Kovalchik KA, MacLennan MS, Peru KM, Headley J V., Chen DDY. 2017. Standard method design considerations for semi-quantification of total naphthenic acids in oil sands process affected water by mass spectrometry: A review. Frontiers of Chemical Science and Engineering 11:497-507. DOI: 10.1007/s11705-017-1652-0. De Laat J, Le TG. 2006. Effects of chloride ions on the iron(III)-catalyzed decomposition 
461

462

463

464

465

466

467

468

469

470

471

472

473

474

475

476

477

478

479

480

481

482

483

484

485

486

487

488

489

490

491

492

493

494

495

496

497

498

499

500

501

502

503

of hydrogen peroxide and on the efficiency of the Fenton-like oxidation process. Applied Catalysis B: Environmental 66:137-146. DOI:

10.1016/j.apcatb.2006.03.008.

Lin L, Jiang W, Chen L, Xu P, Wang H. 2020. Treatment of Produced Water with Photocatalysis: Recent Advances, Affecting Factors and Future Research Prospects. Catalysts 10:924. DOI: 10.3390/catal10080924.

Liu B, Chen B, Zhang B, Song X, Zeng G, Lee K. 2021. Photocatalytic ozonation of offshore produced water by $\mathrm{TiO} 2$ nanotube arrays coupled with UV-LED irradiation. Journal of Hazardous Materials 402:123456. DOI: 10.1016/j.jhazmat.2020.123456.

Lofthus S, Almås IK, Evans P, Pelz O, Brakstad OG. 2018. Biodegradation in seawater of PAH and alkylphenols from produced water of a North Sea platform. Chemosphere 206:465-473. DOI: 10.1016/j.chemosphere.2018.05.006.

Lyngbaek ME, Blidegn LH. 1991. Produced Water Management. In: SPE Health, Safety and Environment in Oil and Gas Exploration and Production Conference. Society of Petroleum Engineers,. DOI: 10.2118/23312-MS.

Marshall AG, Rodgers RP. 2004. Petroleomics: The Next Grand Challenge for Chemical Analysis. Accounts of Chemical Research 37:53-59. DOI: 10.1021/ar020177t.

Meldrum N. 1988. Hydrocyclones: A Solution to Produced-Water Treatment. SPE Production Engineering 3:669-676. DOI: 10.2118/16642-PA.

Murphy RE, Schure MR, Foley JP. 1998. Effect of Sampling Rate on Resolution in Comprehensive Two-Dimensional Liquid Chromatography. Analytical Chemistry 70:1585-1594. DOI: 10.1021/ac971184b.

Niu H, Lee K, Robinson B, Cobanli S, Li P. 2016. Monitoring and modeling the dispersion of produced water on the Scotian Shelf. Environmental Systems Research 5:19. DOI: 10.1186/s40068-016-0070-5.

Norwegian Oil and Gas. 2012. O85 - Norwegian Oil and Gas recommended guidelines for sampling and analysis of produced water.

OSPAR Commission. 2001. Overview assessment of the implementation of OSPAR Recommendation 2001 / 1 for the management of produced water from offshore installations Offshore Industry Series.

Palacio Lozano DC, Thomas MJ, Jones HE, Barrow MP. 2020. Petroleomics: Tools, Challenges, and Developments. Annual Review of Analytical Chemistry 13:405430. DOI: 10.1146/annurev-anchem-091619-091824.

Pannekens M, Kroll L, Müller H, Mbow FT, Meckenstock RU. 2019. Oil reservoirs, an exceptional habitat for microorganisms. New Biotechnology 49:1-9. DOI: 10.1016/j.nbt.2018.11.006.

Di Poi C, Costil K, Bouchart V, Halm-Lemeille M-P. 2018. Toxicity assessment of five emerging pollutants, alone and in binary or ternary mixtures, towards three aquatic organisms. Environmental Science and Pollution Research 25:6122-6134. DOI: 10.1007/s11356-017-9306-9.

Reichenbach SE, Ni M, Zhang D, Ledford EB. 2003. Image background removal in comprehensive two-dimensional gas chromatography. Journal of Chromatography A 985:47-56. DOI: 10.1016/S0021-9673(02)01498-X.

Røe TI, Johnsen S. 1996. Discharges of Produced Water to the North Sea. In: Produced Water 2. Boston, MA: Springer US, 13-25. DOI: 10.1007/978-1-46130379-4_3. 
504 Røe Utvik TI. 1999. Chemical characterisation of produced water from four offshore oil

505

506

507

508

509

510

511

512

513

514

515

516

517

518

519

520

521

522

523

524

525

526

527

528

529

530

531

532

533

534

535

536

537

538

539

540

541

542

543

544

545

546

547

548

549

production platforms in the North Sea. Chemosphere 39:2593-2606. DOI:

10.1016/S0045-6535(99)00171-X.

Samanipour S, Hooshyari M, Baz-Lomba JA, Reid MJ, Casale M, Thomas K V. 2019. The effect of extraction methodology on the recovery and distribution of naphthenic acids of oilfield produced water. Science of The Total Environment 652:1416-1423. DOI: 10.1016/j.scitotenv.2018.10.264.

Samanipour S, Reid MJ, Rundberget JT, Frost TK, Thomas K V. 2020. Concentration and Distribution of Naphthenic Acids in the Produced Water from Offshore Norwegian North Sea Oilfields. Environmental Science \& Technology 54:27072714. DOI: 10.1021/acs.est.9b05784.

Saththasivam J, Loganathan K, Sarp S. 2016. An overview of oil-water separation using gas flotation systems. Chemosphere 144:671-680. DOI: 10.1016/j.chemosphere.2015.08.087.

Schymanski EL, Jeon J, Gulde R, Fenner K, Ruff M, Singer HP, Hollender J. 2014. Identifying Small Molecules via High Resolution Mass Spectrometry: Communicating Confidence. Environmental Science \& Technology 48:2097-2098. DOI: $10.1021 /$ es5002105.

Schymanski EL, Singer HP, Slobodnik J, Ipolyi IM, Oswald P, Krauss M, Schulze T, Haglund P, Letzel T, Grosse S, Thomaidis NS, Bletsou A, Zwiener C, Ibáñez M, Portolés T, de Boer R, Reid MJ, Onghena M, Kunkel U, Schulz W, Guillon A, Noyon N, Leroy G, Bados P, Bogialli S, Stipaničev D, Rostkowski P, Hollender J. 2015. Non-target screening with high-resolution mass spectrometry: critical review using a collaborative trial on water analysis. Analytical and Bioanalytical Chemistry 407:6237-6255. DOI: 10.1007/s00216-015-8681-7.

Sirtori C, Zapata A, Malato S, Agüera A. 2012. Formation of chlorinated by-products during photo-Fenton degradation of pyrimethanil under saline conditions. Influence on toxicity and biodegradability. Journal of Hazardous Materials 217-218:217-223. DOI: 10.1016/j.jhazmat.2012.03.017.

Sørensen L, McCormack P, Altin D, Robson WJ, Booth AM, Faksness L-G, Rowland SJ, Størseth TR. 2019. Establishing a link between composition and toxicity of offshore produced waters using comprehensive analysis techniques - A way forward for discharge monitoring? Science of The Total Environment 694:133682. DOI: 10.1016/j.scitotenv.2019.133682.

Strømgren T, Sørstrøm SE, Schou L, Kaarstad I, Aunaas T, Brakstad OG, Johansen $\varnothing$. 1995. Acute toxic effects of produced water in relation to chemical composition and dispersion. Marine Environmental Research 40:147-169. DOI: 10.1016/01411136(94)00143-D.

Sundberg J, Feilberg KL. 2020. Characterization of heteroatom distributions in the polar fraction of North Sea oils using high-resolution mass spectrometry. Journal of Petroleum Science and Engineering 184:106563. DOI: 10.1016/j.petrol.2019.106563.

Tang Y, Yin M, Yang W, Li H, Zhong Y, Mo L, Liang Y, Ma X, Sun X. 2019. Emerging pollutants in water environment: Occurrence, monitoring, fate, and risk assessment. Water Environment Research 91:984-991. DOI: 10.1002/wer.1163.

The Danish Energy Agency. 2014. Oil and Gas Production in Denmark 2014.

Peerj An. Chem. reviewing PDF | (ACHEM-2020:08:52271:1:2:NEW 9 Mar 2021) 
550 Thomas K V., Langford K, Petersen K, Smith AJ, Tollefsen KE. 2009. Effect-Directed $551 \quad$ Identification of Naphthenic Acids As Important in Vitro Xeno-Estrogens and Anti$552 \quad$ Androgens in North Sea Offshore Produced Water Discharges. Environmental $553 \quad$ Science \& Technology 43:8066-8071. DOI: 10.1021/es9014212. 


\section{Figure 1}

Four representative samples showing the varying oil content.

Photo of four samples after decanting into glass bottles. Only visually clear samples were used in the study (two leftmost), while samples containing oil were excluded (two rightmost). The latter typically contained dispersed oil droplets in the aqueous phase as seen by optical microscopy (Figure 2).






\section{Figure 2}

Optical microscope image (10x magnification) of two different produced water samples.

The image shows the lack (A) or presence (B) of dispersed oil in the aqueous phase. Samples containing dispersed oil were excluded from the study.

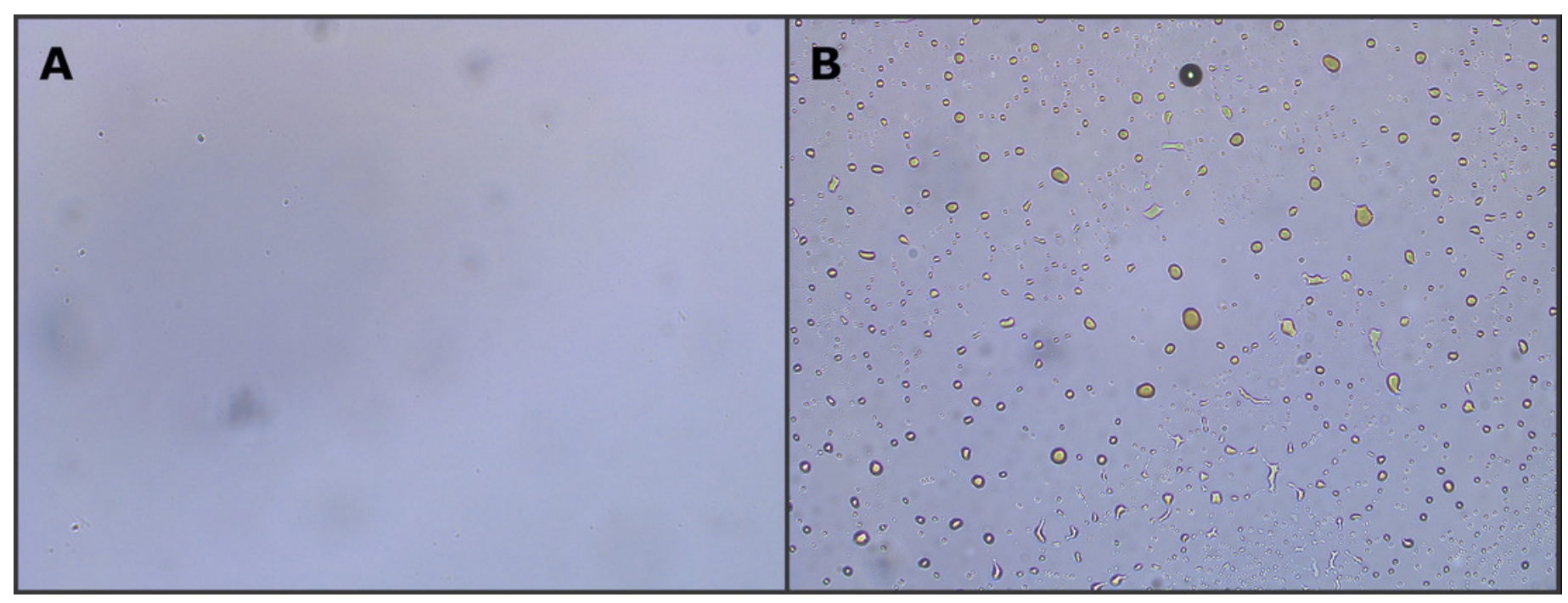




\section{Figure 3}

Example 2D chromatogram showing the distribution of peaks with a heavy saturation of compounds between 0.5 and $1.5 \mathrm{~s}$ in the 2D.

Five representative compounds have been annotated in the chromatogram. The annotation corresponds to; a) Cyclopentylcarboxylic acid, TMS derivative b) Octanoic acid, TMS derivative c) 1-Methylnaphthalene d) Benzoic acid, 3-methyl-, trimethylsilyl ester e) 2Ethyl-1-decanol, TMS derivative

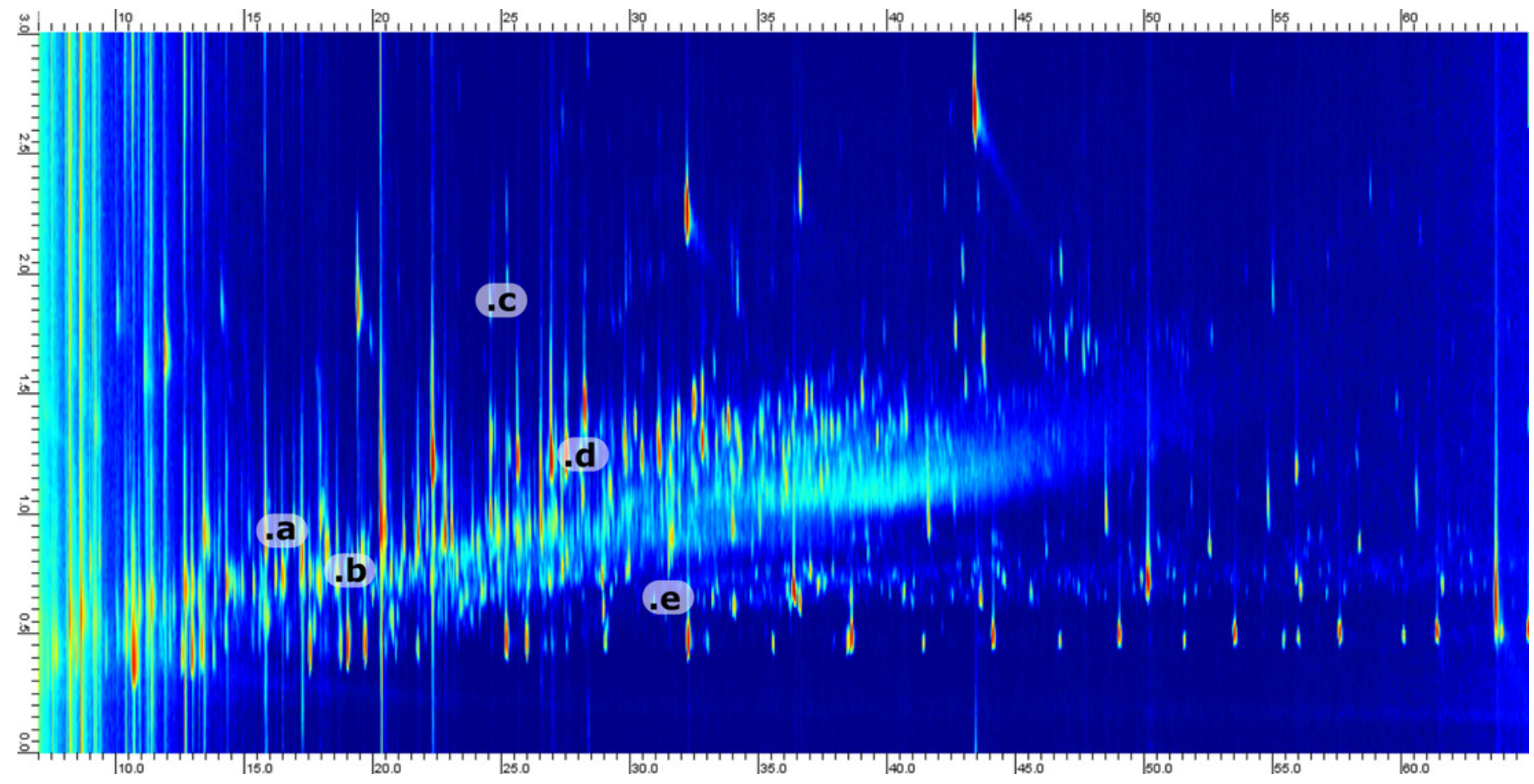


Figure 4

Schematic of the data processing workflow.

Graphic description of how the data processing workflow scores tentatively identified features for added confidence. The scoring was implemented in a Python script and is available as supplementary data.

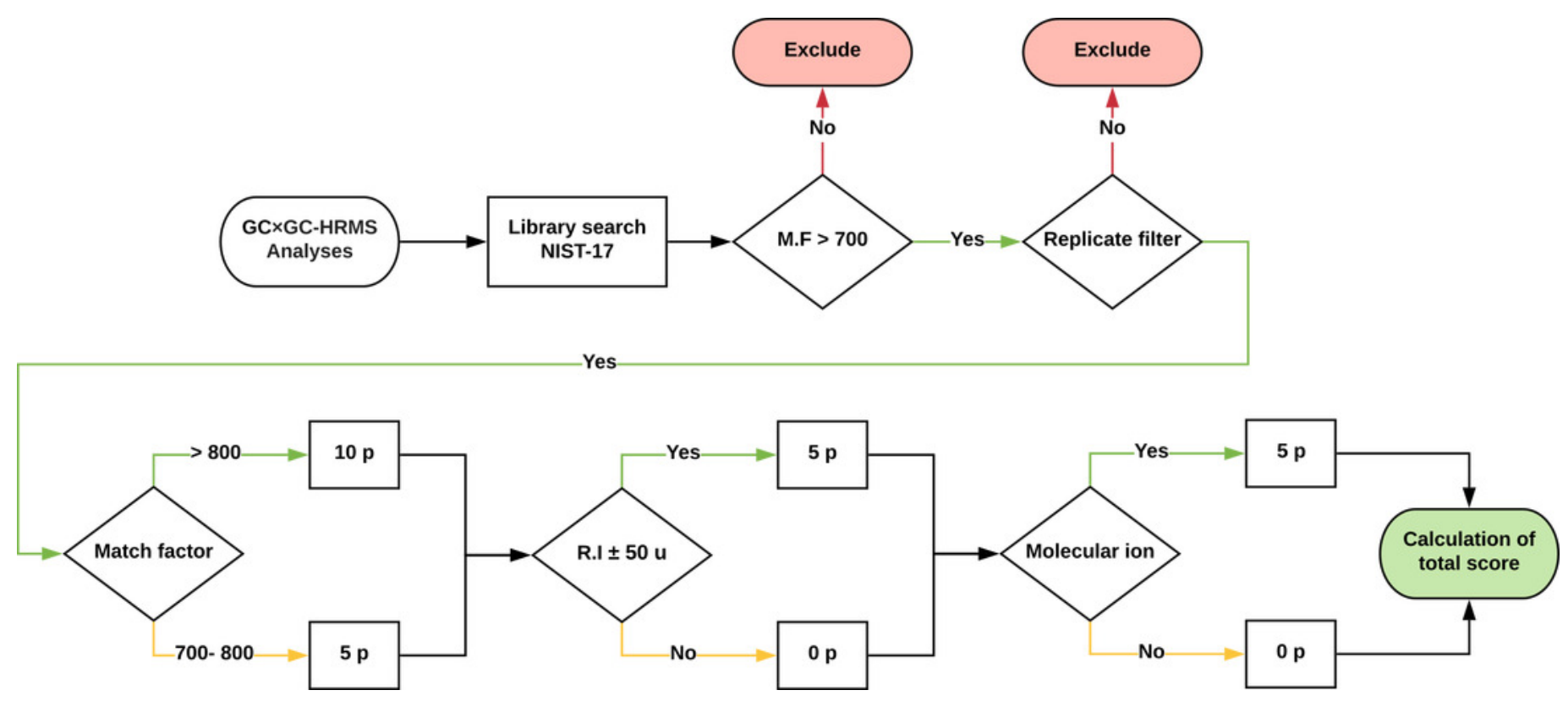




\section{Figure 5}

The molecular structures of six representative compounds.

The structures were obtained from the subset of compounds detected in a minimum of 6 out of 9 samples. LogP/XLogP values were obtained from the PubChem database. The reported retention times are of the corresponding trimethylsilyl derivatives.

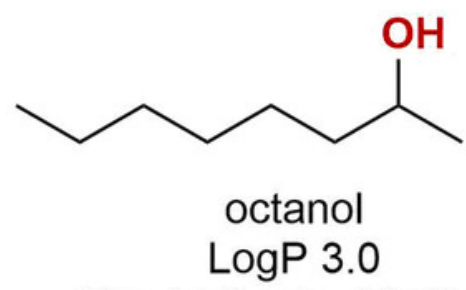

RT: $14.8 \mathrm{~min} . / 0.66 \mathrm{~s}$.<smiles>CCc1ccccc1O</smiles>

2-ethylphenol LogP 2.47

RT: 19.9 min. / $0.93 \mathrm{~s}$.<smiles>O=C(O)C1CCCC1</smiles>

cyclopentylcarboxylic acid XLogP 1.3 RT: 15.8 min. / $0.89 \mathrm{~s}$.<smiles>O=C(O)Cc1ccccc1</smiles>

benzeneacetic acid LogP 1.41

RT: 24.6 min. / $1.31 \mathrm{~s}$.<smiles>CCCCCCCC(=O)O</smiles>

octanoic acid LogP 3.05

RT: 18.9 min. / $0.69 \mathrm{~s}$.<smiles>O=C(O)c1cccc2ccccc12</smiles>

naphthoic acid LogP 3.28

$\mathrm{RT}$ : $42.6 \mathrm{~min} . / 1.75 \mathrm{~s}$. 


\section{Table $\mathbf{1}$ (on next page)}

Extraction recovery and retention time deviations for model and detected compounds

Recovery values are calculated as (peak volume model water $/$ peak volume $\left._{\text {standard }}\right) * 100(\mathrm{n}=4$ for model water and standard, 3 for real-life sample). Retention time deviations were calculated based on the retention of internal standards across all samples $(n=27)$. ${ }^{*}$ Peak volume values were extracted from a representative sample where the compound had been identified. 


\begin{tabular}{|c|c|c|c|c|}
\hline Model compound & Recovery (\%) & \%RSD, model water & \%RSD, standard & \%RSD, real-life sample \\
\hline Phenol & 89.6 & 23.1 & 8.9 & 23.3 \\
\hline Cyclohexanecarboxylic acid & 63.8 & 13.1 & 5.7 & 1.8 \\
\hline Benzoic acid & 35.9 & 24.7 & 1.9 & 11.3 \\
\hline Octanoic acid & 55.0 & 9.6 & 4.4 & 4.2 \\
\hline 2-Naphthoic acid & 88.4 & 9.8 & 3.0 & 5.2 \\
\hline Internal standard & Avg. RT I (min.) & Avg. RT II (sec.) & RT I \%RSD & RT II \%RSD \\
\hline Naphthalene-D8 & 19.399 & 1.860 & 0.0004 & 0.8576 \\
\hline Acenaphthene-D8 & 32.199 & 2.236 & 0.0002 & 0.6218 \\
\hline Phenanthrene & 43.399 & 2.671 & 0.0002 & 0.5178 \\
\hline
\end{tabular}




\section{Table 2 (on next page)}

A list of compounds that were detected in a minimum of 6 of 9 samples.

* The MS-ready name corresponds to the non-derivatized parent compound. Calculated XlogP values were obtained from the PubChem database. \#Samples correspond to the number of samples in which the compound was detected. <!--[if !supportLineBreakNewLine]--> <!-[endif]--> 


\begin{tabular}{|c|c|c|c|c|c|c|c|}
\hline Compound & MS-ready name & Formula & $\begin{array}{l}\text { Mol. } \\
\text { Weight }\end{array}$ & $X \log P$ & SMILES & Classification & $\begin{array}{l}\text { \#Sample } \\
\text { s }\end{array}$ \\
\hline $\begin{array}{l}\text { ( } \pm \text { )-2-Phenylpropanoic Acid, trimethylsilyl } \\
\text { ester }\end{array}$ & 2-phenylpropanoic acid & $\mathrm{C} 9 \mathrm{H} 10 \mathrm{O} 2$ & 150.17 & 1.9 & $\mathrm{CC}(\mathrm{C} 1=\mathrm{CC}=\mathrm{CC}=\mathrm{C} 1) \mathrm{C}(=\mathrm{O}) \mathrm{O}$ & Aromatic acid & 9 \\
\hline 1-Naphthoic acid, TMS derivative & naphthalene-1-carboxylic acid & $\mathrm{C} 11 \mathrm{H} 8 \mathrm{O} 2$ & 172.18 & 3.1 & $\mathrm{C} 1=\mathrm{CC}=\mathrm{C} 2 \mathrm{C}(=\mathrm{C} 1) \mathrm{C}=\mathrm{CC}=\mathrm{C} 2 \mathrm{C}(=\mathrm{O}) \mathrm{O}$ & Aromatic acid & 9 \\
\hline 3,4-Dimethylbenzoic acid, TMS derivative & 3,4-dimethylbenzoic acid & $\mathrm{C} 9 \mathrm{H} 10 \mathrm{O} 2$ & 150.17 & 2.7 & $\mathrm{CC} 1=\mathrm{C}(\mathrm{C}=\mathrm{C}(\mathrm{C}=\mathrm{C} 1) \mathrm{C}(=\mathrm{O}) \mathrm{O}) \mathrm{C}$ & Aromatic acid & 9 \\
\hline Trimethylsilyl 2,3-dimethylbenzoate & 2,3-dimethylbenzoic acid & $\mathrm{C} 9 \mathrm{H} 10 \mathrm{O} 2$ & 150.17 & 2.8 & $\mathrm{CC} 1=\mathrm{C}(\mathrm{C}(=\mathrm{CC}=\mathrm{C} 1) \mathrm{C}(=\mathrm{O}) \mathrm{O}) \mathrm{C}$ & Aromatic acid & 9 \\
\hline Trimethylsilyl 4-propylbenzoate & 4-propylbenzoic acid & $\mathrm{C} 10 \mathrm{H} 12 \mathrm{O} 2$ & 164.2 & 3.4 & $\mathrm{CCCC} 1=\mathrm{CC}=\mathrm{C}(\mathrm{C}=\mathrm{C} 1) \mathrm{C}(=\mathrm{O}) \mathrm{O}$ & Aromatic acid & 9 \\
\hline 4-tert-Butylphenol, TMS derivative & 4-tert-butylphenol & $\mathrm{C} 10 \mathrm{H} 14 \mathrm{O}$ & 150.22 & 3.3 & $\mathrm{CC}(\mathrm{C})(\mathrm{C}) \mathrm{C} 1=\mathrm{CC}=\mathrm{C}(\mathrm{C}=\mathrm{C} 1) \mathrm{O}$ & Aromatic alcohol & 9 \\
\hline $\begin{array}{l}\text { 3-Methyl-1-cyclohexanecarboxylic acid, } \\
\text { trimethylsilyl ester (stereoisomer 2) }\end{array}$ & $\begin{array}{l}\text { 3-methylcyclohexane-1-carboxylic } \\
\text { acid }\end{array}$ & $\mathrm{C} 8 \mathrm{H} 14 \mathrm{O} 2$ & 142.2 & 2.1 & $\operatorname{cc} 1 \operatorname{cccc}(\mathrm{C} 1) \mathrm{C}(=\mathrm{O}) \mathrm{O}$ & Saturated acid & 9 \\
\hline 3-Methylbutanoic acid, TMS derivative & 3-methylbutanoic acid & $\mathrm{C} 5 \mathrm{H} 10 \mathrm{O} 2$ & 102.13 & 1.2 & $\mathrm{CC}(\mathrm{C}) \mathrm{CC}(=\mathrm{O}) \mathrm{O}$ & Saturated acid & 9 \\
\hline Cyclohexaneacetic acid, TMS derivative & 2-cyclohexylacetic acid & $\mathrm{C} 8 \mathrm{H} 14 \mathrm{O} 2$ & 142.2 & 2.5 & $\mathrm{C} 1 \mathrm{CCC}(\mathrm{CC} 1) \mathrm{CC}(=\mathrm{O}) \mathrm{O}$ & Saturated acid & 9 \\
\hline Cyclohexanecarboxylic acid, TMS derivative & cyclohexanecarboxylic acid & $\mathrm{C} 7 \mathrm{H} 12 \mathrm{O} 2$ & 128.17 & 1.9 & $\mathrm{C} 1 \mathrm{CCC}(\mathrm{CC} 1) \mathrm{C}(=\mathrm{O}) \mathrm{O}$ & Saturated acid & 9 \\
\hline Cyclopentylcarboxylic acid, TMS derivative & cyclopentanecarboxylic acid & $\mathrm{C} 6 \mathrm{H} 10 \mathrm{O} 2$ & 114.14 & 1.3 & $\mathrm{C} 1 \mathrm{CCC}(\mathrm{C} 1) \mathrm{C}(=\mathrm{O}) \mathrm{O}$ & Saturated acid & 9 \\
\hline Heptanoic acid, TMS derivative & heptanoic acid & $\mathrm{C} 7 \mathrm{H} 14 \mathrm{O} 2$ & 130.18 & 2.5 & $\operatorname{ccccccc}(=0) 0$ & Saturated acid & 9 \\
\hline Nonanoic acid, TMS derivative & nonanoic acid & $\mathrm{C} 9 \mathrm{H} 18 \mathrm{O} 2$ & 158.24 & 3.5 & $\operatorname{ccccccccc}(=0) 0$ & Saturated acid & 9 \\
\hline Octanoic acid, TMS derivative & octanoic acid & $\mathrm{C} 8 \mathrm{H} 16 \mathrm{O} 2$ & 144.21 & 3 & $\operatorname{cccccccc}(=0) 0$ & Saturated acid & 9 \\
\hline 1-Hexadecanol, TMS derivative & hexadecan-1-ol & $\mathrm{C} 16 \mathrm{H} 34 \mathrm{O}$ & 242.44 & 7.3 & 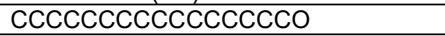 & Saturated alcohol & 9 \\
\hline Benzenepropanoic acid, TMS derivative & 3-phenylpropanoic acid & $\mathrm{C} 9 \mathrm{H} 10 \mathrm{O} 2$ & 150.17 & 1.8 & $\mathrm{C} 1=\mathrm{CC}=\mathrm{C}(\mathrm{C}=\mathrm{C} 1) \mathrm{CCC}(=\mathrm{O}) \mathrm{O}$ & Aromatic acid & 8 \\
\hline m-Toluic acid, TMS derivative & 3-methylbenzoic acid & $\mathrm{C} 8 \mathrm{H} 8 \mathrm{O} 2$ & 136.15 & 2.4 & $\mathrm{CC} 1=\mathrm{CC}(=\mathrm{CC}=\mathrm{C} 1) \mathrm{C}(=\mathrm{O}) \mathrm{O}$ & Aromatic acid & 8 \\
\hline 2,4-Di-tert-butylphenol & 2,4-ditert-butylphenol & $\mathrm{C} 14 \mathrm{H} 22 \mathrm{O}$ & 206.32 & 4.9 & $\mathrm{CC}(\mathrm{C})(\mathrm{C}) \mathrm{C} 1=\mathrm{CC}(=\mathrm{C}(\mathrm{C}=\mathrm{C} 1) \mathrm{O}) \mathrm{C}(\mathrm{C})(\mathrm{C}) \mathrm{C}$ & Aromatic alcohol & 8 \\
\hline 3-Ethylphenol, TMS derivative & 3-ethylphenol & $\mathrm{C} 8 \mathrm{H} 10 \mathrm{O}$ & 122.16 & 2.4 & $\mathrm{CCC} 1=\mathrm{CC}(=\mathrm{CC}=\mathrm{C} 1) \mathrm{O}$ & Aromatic alcohol & 8 \\
\hline 4-Isopropylphenol, TMS derivative & 4-propan-2-ylphenol & $\mathrm{C} 9 \mathrm{H} 12 \mathrm{O}$ & 136.19 & 2.9 & $\mathrm{CC}(\mathrm{C}) \mathrm{C} 1=\mathrm{CC}=\mathrm{C}(\mathrm{C}=\mathrm{C} 1) \mathrm{O}$ & Aromatic alcohol & 8 \\
\hline o-Cresol, TMS derivative & 2-methylphenol & $\mathrm{C} 7 \mathrm{H} 8 \mathrm{O}$ & 108.14 & 2 & $\mathrm{CC} 1=\mathrm{CC}=\mathrm{CC}=\mathrm{C} 1 \mathrm{O}$ & Aromatic alcohol & 8 \\
\hline 2-Methylbutanoic acid, TMS derivative & 2-methylbutanoic acid & $\mathrm{C} 5 \mathrm{H} 10 \mathrm{O} 2$ & 102.13 & 1.2 & $\operatorname{ccc}(\mathrm{C}) \mathrm{C}(=\mathrm{O}) \mathrm{O}$ & Saturated acid & 8 \\
\hline 3-Methylvaleric acid, TMS & 3-methylpentanoic acid & $\mathrm{C} 6 \mathrm{H} 12 \mathrm{O} 2$ & 116.16 & 1.6 & $\operatorname{ccc}(\mathrm{C}) \operatorname{cc}(=0) \mathrm{O}$ & Saturated acid & 8 \\
\hline 2-Octanol, TMS derivative & octan-2-ol & $\mathrm{C} 8 \mathrm{H} 18 \mathrm{O}$ & 130.23 & 2.9 & $\operatorname{ccccccc}(\mathrm{C}) \mathrm{O}$ & Saturated alcohol & 8 \\
\hline Benzeneacetic acid, TMS derivative & 2-phenylacetic acid & $\mathrm{C} 8 \mathrm{H} 8 \mathrm{O} 2$ & 136.15 & 1.4 & $\mathrm{C} 1=\mathrm{CC}=\mathrm{C}(\mathrm{C}=\mathrm{C} 1) \mathrm{CC}(=\mathrm{O}) \mathrm{O}$ & Aromatic acid & 7 \\
\hline Benzenebutanoic acid, TMS derivative & 4-phenylbutanoic acid & $\mathrm{C} 10 \mathrm{H} 12 \mathrm{O} 2$ & 164.2 & 2.4 & $\mathrm{C} 1=\mathrm{CC}=\mathrm{C}(\mathrm{C}=\mathrm{C} 1) \operatorname{CCCC}(=\mathrm{O}) \mathrm{O}$ & Aromatic acid & 7 \\
\hline m-Cresol, TMS derivative & 3-methylphenol & $\mathrm{C} 7 \mathrm{H} 8 \mathrm{O}$ & 108.14 & 2 & $\mathrm{CC} 1=\mathrm{CC}(=\mathrm{CC}=\mathrm{C} 1) \mathrm{O}$ & Aromatic alcohol & 7 \\
\hline $\begin{array}{l}\text { 2-Hydroxy-4-methylquinoline, trimethylsilyl } \\
\text { ether }\end{array}$ & 4-methyl-1H-quinolin-2-one & $\mathrm{C} 10 \mathrm{H} 9 \mathrm{NO}$ & 159.18 & 1.2 & $\mathrm{CC} 1=\mathrm{CC}(=\mathrm{O}) \mathrm{NC} 2=\mathrm{CC}=\mathrm{CC}=\mathrm{C} 12$ & $\begin{array}{l}\text { Aromatic } \\
\text { amine/alcohol }\end{array}$ & 7 \\
\hline 4-Methylvaleric acid, TMS derivative & 4-methylpentanoic acid & $\mathrm{C} 6 \mathrm{H} 12 \mathrm{O} 2$ & 116.16 & 1.4 & $\mathrm{CC}(\mathrm{C}) \mathrm{CCC}(=0) \mathrm{O}$ & Saturated acid & 7 \\
\hline 2-Ethylphenol, TMS derivative & 2-ethylphenol & $\mathrm{C} 8 \mathrm{H} 10 \mathrm{O}$ & 122.16 & 2.5 & $\mathrm{CCC} 1=\mathrm{CC}=\mathrm{CC}=\mathrm{C} 1 \mathrm{O}$ & Aromatic alcohol & 6 \\
\hline 4-Trimethylsilylphenol & phenol & $\mathrm{C} 6 \mathrm{H} 6 \mathrm{O}$ & 94.11 & 1.5 & $\mathrm{C} 1=\mathrm{CC}=\mathrm{C}(\mathrm{C}=\mathrm{C} 1) \mathrm{O}$ & Aromatic alcohol & 6 \\
\hline Benzoic acid, 4-ethoxy-, ethyl ester & ethyl 4-ethoxybenzoate & $\mathrm{C} 11 \mathrm{H} 14 \mathrm{O} 3$ & 194.23 & 3.2 & $\mathrm{CCOC} 1=\mathrm{CC}=\mathrm{C}(\mathrm{C}=\mathrm{C} 1) \mathrm{C}(=\mathrm{O}) \mathrm{OCC}$ & Aromatic ester & 6 \\
\hline Naphthalene, 1,7-dimethyl- & 1,7-dimethylnaphthalene & $\mathrm{C} 12 \mathrm{H} 12$ & 156.22 & 4.4 & $\mathrm{CC} 1=\mathrm{CC} 2=\mathrm{C}(\mathrm{C}=\mathrm{CC}=\mathrm{C} 2 \mathrm{C}=\mathrm{C} 1) \mathrm{C}$ & Aromatic hydrocarbon & 6 \\
\hline $\begin{array}{l}\text { 3-Methyl-1-cyclohexanecarboxylic acid, } \\
\text { trimethylsilyl ester (stereoisomer 1) }\end{array}$ & $\begin{array}{l}\text { 3-methylcyclohexane-1-carboxylic } \\
\text { acid }\end{array}$ & $\mathrm{C} 8 \mathrm{H} 14 \mathrm{O} 2$ & 142.2 & 2.1 & $\operatorname{cc} 1 \operatorname{cccc}(\mathrm{C} 1) \mathrm{C}(=\mathrm{O}) \mathrm{O}$ & Saturated acid & 6 \\
\hline Pentanoic acid, TMS derivative & pentanoic acid & $\mathrm{C} 5 \mathrm{H} 10 \mathrm{O} 2$ & 102.13 & 1.4 & $\operatorname{ccccc}(=0) \mathrm{O}$ & Saturated acid & 6 \\
\hline 2-(1-Adamantyl)ethanol, TMS derivative & 2-(1-adamantyl)ethanol & $\mathrm{C} 12 \mathrm{H} 20 \mathrm{O}$ & 180.29 & 3.4 & $\mathrm{C} 1 \mathrm{C} 2 \mathrm{CC} 3 \mathrm{CC} 1 \mathrm{CC}(\mathrm{C} 2)(\mathrm{C} 3) \mathrm{CCO}$ & Saturated alcohol & 6 \\
\hline
\end{tabular}

